\title{
Train-of-four fade and neuromuscular block in \\ rats: a comparison between pancuronium, vecuronium, and rocuronium
}

\author{
H. Itoh MD, \\ K. Shibata MD, \\ S. Nitta MD, * \\ T. Kobayashi MD
}

Purpose: To clarify the relationship between neuromuscular block and train-of-four fade and to investigate the causes of these drug-dependent differences, we compared the neuromuscular block and TOF fade after pancuronium, vecuronium and rocuronium.

Methods: In 24 anesthetized rats, the sciatic nerve was stimulated, and the twitch of left tibialis anterior muscle was recorded. After $T_{1}$ (first twitch response) was kept constant at $95 \%$ block by administration of pancuronium, vecuronium, or rocuronium ( $n=8$, in each), the TOF fade was measured when T, block was decreased to $40 \%$ and $20 \%$. In addition, using 24 phrenic nerve-diaphragm preparations, the fade was measured when the $\mathrm{T}$, block increased to $20 \%$ and $40 \%$ by titrating of either one of the three drugs ( $n=8$, in each).

Results: In in vivo experiments, the fade produced by pancuronium was greater than that by vecuronium or rocuronium when $T$, block was at $40 \%$ ( $81 \pm 9$ vs $63 \pm 15$ and $63 \pm 6 \%$, respectively) and at $20 \%$ (66 \pm 13 vs $34 \pm 17$ and $40 \pm 6 \%$, respectively). In contrast, in in vitro experiments, the differences did not reach significant levels among the three drugs either at 20\% (32 \pm 19 vs $33 \pm 10$ and $32 \pm 17 \%)$ or $40 \%$ of block (62 \pm 29 vs $65 \pm 14$ and $55 \pm 14 \%$ ).

Conclusions: For vecuronium and rocuronium, the results were similar in vivo and in vitro. For pancuronium, fade was greater in vivo. These results suggest that different neuromuscular blocking agent have different relationships between the fade and the block. In vitro results might not be the same as in vivo, possibly due to pharmacokinetic differences.

Objectif : Clarifier la relation entre le blocage neuromusculaire et l'affaiblissement de la réaction aux stimulations musculaires en train-de-quatre. De plus, comparer le bloc et l'affaissement du TDQ obtenu avec le pancuronium, le vécuronium et le rocuronium, et rechercher les causes des différences.

Méthode : On a stimulé le nerf sciatique chez 24 rats anesthésiés et on a enregistré la contraction (twitch T) du muscle jambier antérieur gauche. Après avoir atteint un $T$, constant (réponse à la première stimulation) avec un bloc à $95 \%$ en administrant du pancuronium, du vécuronium ou du rocuronium ( $\mathrm{n}=8$ dans chaque cas), l'affaissement du TDQ a été mesurée lorsque le bloc était réduit à $40 \%$ et à $20 \%$. De plus, en utilisant 24 préparations de diaphragme-nerf phrénique, l'affaissement a été mesuré lorsque le bloc à $T$, a été augmenté à $20 \%$ et à $40 \%$ en dosant l'un des trois médicaments ( $n=8$ dans chaque cas).

Résultats : Dans les expériences in vivo, l'affaissement produit par le pancuronium a été plus grand que celui qui a été provoqué par le vécuronium ou le rocuronium lorsque le bloc à $T$, était à $40 \%$ (8I \pm 9 vs $63 \pm 15$ et 63 $\pm 6 \%$, respectivement) et à $20 \%$ ( $66 \pm 13$ vs $34 \pm 17$ et $40 \pm 6 \%$, respectivement). Par ailleurs, dans les expériences in vitro, les différences n'étaient pas significatives entre les trois médicaments, que ce soit un bloc à $20 \%(32 \pm 19$ vs $33 \pm 10$ et $32 \pm 17 \%)$ ou un bloc à $40 \%$ (62 \pm 29 vs $65 \pm 14$ et $55 \pm 14 \%)$.

Conclusion : Les résultats d'expériences in vivo et in vitro ont été similaires avec le vécuronium et le rocuronium. L'affaissement du TDQ a été plus important avec le pancuronium lors d'expériences in vivo. Ces résultats suggèrent que différents myorelaxants présentent des liens différents entre l'affaissement du TDQ et le bloc. Les résultats différents entre les expériences in vitro et in vivo peuvent provenir de différences pharmacocinétiques.

From the Department of Anesthesiology and Intensive Care Medicine, School of Medicine, Kanazawa University, and the Department of Anesthesia, ${ }^{*}$ Ishikawa Prefectural Central Hospital, Japan.

Address correspondence to: Hironori Itoh MD, Department of Anesthesiology and Intensive Care Medicine, School of Medicine,

Kanazawa University, 13-1 Takara-machi, Kanazawa 920-8641, Japan. Phone: +81-76-265-2433; Fax: +81-76-234-4267;

E-mail: hironori@med.kanazawa-u.ac.jp

Support: Neuromuscular blocking agents were provided by Organon Inc.

Accepted for publication July 1, 2000. 
RAIN-OF-FOUR(TOF) fade is used clinically as an index of the degree of neuromuscular block produced by administration of a non-depolarizing neuromuscular blocking agent (NBA). Although it is generally accepted that the relationship between the TOF fade and neuromuscular block is constant, ${ }^{1,2}$ previous clinical reports have shown differences in the magnitude of the TOF fade during the recovery phase for different NBA at the same level of neuromuscular block. ${ }^{3-6}$ While nondepolarizing NBAs act mainly at the postjunctional site, some investigators have suggested that they also have a prejunctional effect that is responsible for the TOF fade. ${ }^{7-11}$ Consequently, drug-dependent differences in TOF fade are believed to be a function of their prejunctional potency., ${ }^{5,10,12-14}$ However, Storella et al. ${ }^{15}$ suggested that the differences observed clinically may be due to pharmacokinetic differences among drugs rather than any pharmacodynamic difference in potency at the site of action.

The present study was undertaken to determine whether drug-dependent differences exist between the TOF fade and neuromuscular block, and if drug-dependent differences do exist, to identify differences in the prejunctional potency of NBAs at the neuromuscular junction. In vivo and in vitro, neuromuscular preparations from rats were used to create a clinical and a steady-state model, respectively. We compared the TOF fade produced by three drugs, pancuronium, vecuronium, and rocuronium, in these two different models.

Materials and methods

Male Sprague-Dawley rats weighing between 300 and $450 \mathrm{~g}$ were used in all experiments. The experimental protocol was approved by our Institutional Animal Care and Use Committee.

\section{IN VIVO EXPERIMENT}

Twenty-four rats were anesthetized with $30 \mathrm{mg} \cdot \mathrm{kg}^{-1}$ pentobarbitone and $500 \mathrm{mg} \cdot \mathrm{kg}^{-1}$ urethane, ip, if necessary, followed by $15 \mathrm{mg} \cdot \mathrm{kg}^{-1}$ and $250 \mathrm{mg} \cdot \mathrm{kg}^{-1}$, respectively. Tracheostomy was performed, and the lungs of each rat were ventilated with $\mathrm{O}_{2} 100 \%$ adjusted to maintain the arterial $\mathrm{CO}_{2}$ tension at about 40 $\mathrm{mmHg}$. The left external jugular vein and the internal carotid artery were cannulated for administration of the NBAs and to record the arterial blood pressure, respectively. Rectal temperature was maintained between 36 and $37^{\circ} \mathrm{C}$ with an incubator. The sciatic nerve was dissected from the gluteal space and ligated, and bipolar platinum electrodes were attached to the peripheral portion of the nerve. The distal tendon of the left tibialis anterior muscle was isolated from the surrounding tissue and connected to a force transducer (TB-611, Nihon Kohden, Tokyo, Japan) at a resting tension of $30 \mathrm{~g}$. TOF stimulation (SEN-7103 stimulator, Nihon Kohden), consisting of four supramaximal pulses, was applied to the sciatic nerve by the bipolar platinum electrodes every $20 \mathrm{sec}$. The duration and the frequency of the pulses were $0.2 \mathrm{msec}$ and $2 \mathrm{~Hz}$, respectively. Neuromuscular block was monitored by measuring the $\mathrm{Tl}$ (first twitch response in TOF stimulation) and TOF fade, which were calculated, as follows:

Tl block $(\%)=100 \times(\mathrm{C}-\mathrm{Tl}) / \mathrm{C}$

Fade $(\%)=100 \times(\mathrm{Tl}-\mathrm{T} 4) / \mathrm{Tl}$

Where $\mathrm{C}$ is the control tension before the NBA is added, and $\mathrm{T}_{4}$ is the tension produced by the last twitch response in the TOF stimulation.

Rats were assigned to one of three groups according to NBAs: pancuronium, vecuronium, or rocuronium (n $=8$, in each). Following stabilization of responses and determination of the control tension, a continuous infusion of a NBA was started. The infusion rate was adjusted to maintain the $\mathrm{T}_{1}$ block at about $95 \%$. The infusion rate was kept constant at this $\mathrm{T}_{1}$ block for at least $30 \mathrm{~min}$, after which the infusion was discontinued. During recovery from neuromuscular block, the TOF fade was determined when the $\mathrm{T}_{1}$ block reached the point nearest $40 \%$ and $20 \%$. In addition, the recovery index (time required for the $\mathrm{T}_{1}$ block to recover from $75 \%$ to $25 \%$ ) was recorded.

\section{IN VITRO EXPERIMENT}

Twelve rats were anesthetized with halothane and sacrificed. The right and left hemidiaphragms with accompanying phrenic nerves were dissected out to yield 24 phrenic nerve-hemidiaphragm preparations. Each preparation was placed vertically in an individual organ bath filled with $100 \mathrm{ml}$ modified Krebs' solution ${ }^{16}$ with the following composition: $\mathrm{NaCl} 113 \mathrm{mM}$, $\mathrm{KCl} 4.7 \mathrm{mM}, \mathrm{CaCl}_{2} 1.4 \mathrm{mM}, \mathrm{NaHCO}_{3} 25 \mathrm{mM}$, $\mathrm{MgSO}_{4} 0.9 \mathrm{mM}, \mathrm{KH}_{2} \mathrm{PO}_{4} 1.2 \mathrm{mM}$, and glucose 11.5 $\mathrm{mM}$. The solution in the bath was aerated with $95 \%$ $\mathrm{O}_{2} / 5 \% \mathrm{CO}_{2}$, and its temperature and $\mathrm{pH}$ were maintained at $37^{\circ} \mathrm{C}$ and between 7.38 and 7.42 , respectively. The tendon of the hemidiaphragm was connected to a force transducer to record muscle contraction, and the muscle was stretched to a resting tension of $10 \mathrm{~g}$. TOF stimulation using the same pattern and interval as described in the in vivo experiment was applied to the phrenic nerve.

As in the in vivo experiment, rats were assigned to one of three groups: pancuronium, vecuronium, or 
rocuronium groups $(\mathrm{n}=8$, in each). Each group included equal numbers of left and right hemidiaphragms. After measurement of baseline tension, the concentration of the NBA in the bath was increased gradually until $\mathrm{T}_{1}$ block reached about $20 \%$. Initial doses of pancuronium, vecuronium, and rocuronium were 1.5, 3.0, and $8.0 \mu \mathrm{M}$, respectively. The initial doses were determined with other preparations in a similar experimental model in a preliminary investigations. The doses were adjusted by adding the agent or modified Krebs' solution. At least $30 \mathrm{~min}$ was allowed to establish a pseudosteady-state condition for the drug concentration between the bath and the preparation, and the TOF fade was measured. Then the drug concentration was increased until the $\mathrm{T}_{1}$ block reached about $40 \%$, and after $30 \mathrm{~min}$, the TOF fade was measured again. The solution in the bath was replaced with $100 \mathrm{ml}$ of modified Krebs' solution without NBAs, and recovery from neuromuscular block was monitored.

\section{Statistical analysis}

Results are expressed as the mean \pm SD. Statistical analysis was performed by one-way analysis of variance with Scheffe's multiple comparison. Differences were considered significant at $P<.05$.

Results

IN VIVO EXPERIMENT

The actual $\mathrm{T}_{1}$ block during the drug infusion were almost $95 \%$ in three groups (Table I). The actual $\mathrm{T}_{1}$ block at the time the TOF fade was measured for the $40 \%$ and $20 \%$ data points were considered acceptably close to $40 \%$ and $20 \%$ block to permit comparison among groups. At both points, the TOF fade in the pancuronium group was greater than in the vecuronium or rocuronium groups. These differences between drugs (pancuronium vs vecuronium and rocuronium) were observed not only at 20 and $40 \%$ block (Figure). The difference did not reach to significant level in the TOF fade between the vecuronium and rocuronium groups at either $40 \%$ or $20 \%$ of $\mathrm{Tl}$ block $(P=.95)$. The recovery index of the pancuronium group was longer than those of the other two groups. The difference did not reach to significant level in the recovery indices between the vecuronium and rocuronium groups $(P=$ $.65)$. All subjects recovered over $90 \%$ of initial control twitch.

\section{IN VITRO EXPERIMENT}

The actual $\mathrm{T}_{1}$ block at the time the TOF fade was measured for the $20 \%$ and $40 \%$ data points were considered acceptably close to $20 \%$ or $40 \%$ to permit comparisons between groups. At either degree of $\mathrm{T}_{1}$ block,
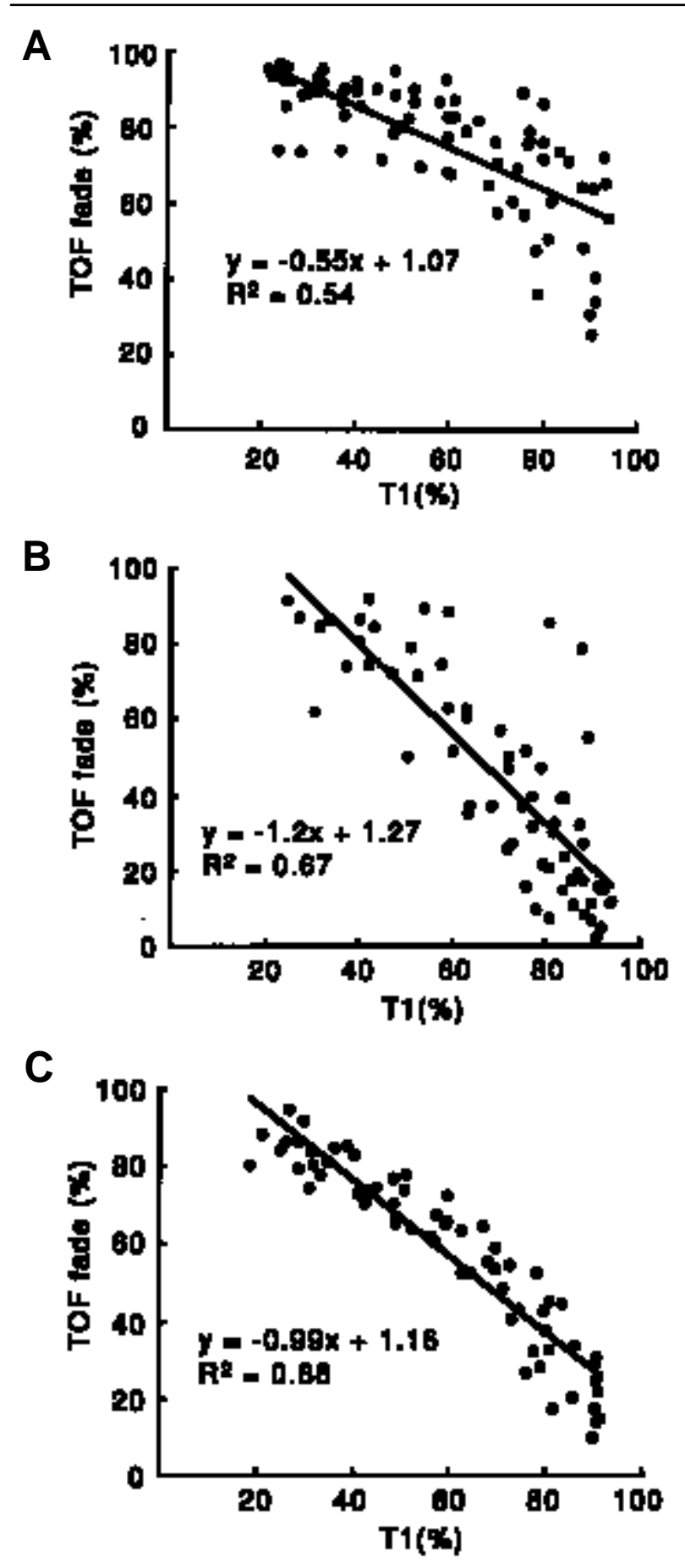

FIGURE Recovery of Tl vs TOF fade. A: Pancuronium; B: Vecuronium; C: Rocuronium.

the differences did not reach significant levels in the TOF fade between groups $(P=.98, .60$, respectively, Table II). Thus, for vecuronium and rocuronium, the 
TABLE I Data in vivo experiment

\begin{tabular}{llll}
\hline & Pancuronium & Vecuronium & Rocuronium \\
\hline $\begin{array}{l}\text { Infusion rate } \\
\left(\mu \mathrm{g} \cdot \mathrm{kg}^{-1} \cdot \mathrm{min}^{-1}\right)\end{array}$ & $6.4 \pm 3.0$ & $64 \pm 22^{*}$ & $140 \pm 45^{*} \dagger$ \\
$\begin{array}{l}\text { Actual Tl block (\%) } \\
\text { during drug infusion }\end{array}$ & $95.8 \pm 1.7$ & $95.6 \pm 2.2$ & $96.7 \pm 0.6$ \\
$\begin{array}{l}\text { Actual Tl block (\%) } \\
\text { 20\% data points }\end{array}$ & $20.2 \pm 0.9$ & $19.4 \pm 1.4$ & $20.6 \pm 0.9$ \\
$\quad 40 \%$ data points & $40.0 \pm 0.4$ & $39.9 \pm 2.9$ & $39.7 \pm 2.2$ \\
$\begin{array}{l}\text { TOF fade (\%) } \\
\text { 20\% block }\end{array}$ & $66.3 \pm 13.4$ & $33.8 \pm 16.7^{*} 39.9 \pm 9.6^{*}$ \\
$\quad 40 \%$ block & $81.1 \pm 9.4$ & $63.1 \pm 15.0^{*} 62.8 \pm 6.3^{*}$ \\
Recovery index & & & \\
$\quad(\mathrm{sec})$ & $520 \pm 270$ & $85 \pm 33^{*}$ & $160 \pm 32^{*}$ \\
\hline
\end{tabular}

Values are mean $\pm \mathrm{SD} ; \mathrm{n}=8$ for each group.

${ }^{*} P<.01$ vs pancuronium.

$\dagger P<.01$ vs vecuronium.

TABLE II Data in vitro experiment

\begin{tabular}{llll}
\hline & Pancuronium Vecuronium & Rocuronium \\
\hline Concentration $(\mu \mathrm{M})$ & & & \\
$20 \%$ block & $1.6 \pm 0.4$ & $3.0 \pm 0.4^{*}$ & $7.4 \pm 1.5^{*} \dagger$ \\
$\quad 40 \%$ block & $1.8 \pm 0.5$ & $3.6 \pm 0.5^{*}$ & $8.8 \pm 1.4^{*} \dagger$ \\
Actual Tl block $(\%)$ & & & \\
$\quad 20 \%$ data points & $20.4 \pm 1.1$ & $20.2 \pm 0.7$ & $20.7 \pm 2.2$ \\
40\% data points & $39.9 \pm 1.1$ & $39.8 \pm 0.9$ & $41.4 \pm 2.4$ \\
TOF fade (\%) & & & \\
20\% block & $32.0 \pm 18.5$ & $32.9 \pm 9.5$ & $31.7 \pm 16.8$ \\
$40 \%$ block & $62.1 \pm 28.9$ & $64.5 \pm 13.9$ & $54.6 \pm 14.3$ \\
\hline
\end{tabular}

Values are mean $\pm \mathrm{SD} ; \mathrm{n}=8$ for each group.

${ }^{*} P<.01$ vs pancuronium.

$\dagger P<.01$ vs vecuronium.

results were similar in vivo and in vitro. In contrast, for pancuronium, fade was greater in vivo. The $\mathrm{Tl}$ recovered to over $90 \%$ of initial control twitch in all preparations following replacement of the organ bath with modified Krebs' solution without NBA.

\section{Discussion}

Train-of-four fade is not necessarily different in vivo and in vitro, but the differences between drugs in vivo might not be found in vitro. In previous studies in humans, it was noted that TOF fade depends not only on the drug but also on the size of a single bolus dose. ${ }^{3,12}$ To exclude this dose-dependent effect, we collected data in vivo during recovery from a uniform degree of neuromuscular block. Given that the $T_{1}$ block was stable for at least $30 \mathrm{~min}$ prior to data collection, a pseudo-steady-state for drug distribution between plasma and muscle is assumed to have been reached. Although the in vitro experiment showed no drug-dependent differences in TOF fade at a given degree of neuromuscular block, TOF fade was greater with pancuronium than with vecuronium or rocuronium in vivo.

It has been suggested that acetylcholine ( $\mathrm{ACh}$ ) released at the neuromuscular junction stimulates prejunctional receptors and facilitates the mobilization of ACh from reserve stores to the immediately available store. This is why the output of ACh can keep up with the demands of repetitive stimulation. ${ }^{10} \mathrm{~A}$ block by non-depolarizing NBAs would lead to a progressive decrease in the amount of ACh released per stimulus during TOF stimulation, accounting for the TOF fade phenomenon. ${ }^{8,17,18}$ Based on this mechanism, differences among drugs in the production of the TOF fade can be accounted for by different affinities for prejunctional receptors, i.e., the greater the affinity, the greater the TOF fade. ${ }^{5,10,12-14}$ If drug-dependent differences in TOF fade are determined pharmacodynamically, as with affinity for prejunctional receptors, the experiments studying this relationship should be performed under pseudo-steady-state conditions, such as in an organ bath. An organ bath allows the drug concentration to equilibrate between the bath and the neuromuscular junction and between the prejunctional and postjunctional sites, and fails to account for differences in the rate of drug diffusion and elimination. The lack of differences in TOF fade in vitro between pancuronium, vecuronium, or rocuronium suggests that there are no differences in the affinity for prejunctional receptors between these three NBAs.

Two in vivo studies have examined the differences in the TOF fade between pancuronium and vecuronium, ${ }^{4,19}$ and both investigations concluded that pancuronium caused a greater TOF fade than vecuronium during recovery from neuromuscular block. Additionally, Shiraishi et al. ${ }^{19}$ demonstrated that the TOF fade produced by rocuronium is less than that produced by pancuronium. These results support our findings.

Few studies have addressed TOF fade produced by NBAs under steady-state conditions. ${ }^{15,20}$ When TOF fade at a given degree of neuromuscular block is measured at steady-state, its value is determined by the relative difference between the pre and postjunctional effects. It is possible that the TOF fade at steady-state is different for different NBAs in vivo, since the rate of drug distribution and elimination may influence the time-course of $\mathrm{T}_{4}$ relative to $\mathrm{T}_{1}$, and the pharmacokinetic differences among the three NBAs may cause the differences in TOF fade. It has been reported that plasma concentrations of vecuronium and rocuronium decrease more rapidly than the concentration of pan- 
curonium ${ }^{21,22}$ which is supported by our experiments. Because the infusion rate necessary to maintain a $95 \%$ block in vivo was approximately 10 and 25 times higher with vecuronium and rocuronium than with pancuronium, although the potencies of vecuronium and rocuronium are one half and one-fifth of pancuronium's in vitro.

In humans, the block/fade relationship following a single bolus of a NBA differs depending on the phase of neuromuscular block, i.e., all NBAs used clinically show less TOF fade during onset than during recovery. ${ }^{3,10,12,23}$ Bartkowski et al. ${ }^{24}$ have explained this difference based on pharmacokinetic differences between muscle compartments. Generally a muscle is composed of several compartments with regard to the rate of drug distribution and elimination. ${ }^{15,25}$ These authors concluded that a rapid change (not only an increase but also a decrease) in the plasma NBA concentration diminish the TOF fade. We believe that the rapid changes in the plasma concentrations associated with vecuronium and rocuronium distribution affected their TOF fade. Consequently, even though the prejunctional effect of the NBAs used in this study was the same, as shown by the similarity of the TOF fade at pseudo-steady-state in vitro, the effect of these agents in vivo is different because the pharmacokinetics affect the degree of prejunctional block. This proposed mechanism of action may account for the difference in TOF fade observed during in vivo and in vitro conditions, but fade in vitro would be expected to be closer in the case of drugs whose concentration change little in vivo, compared with drugs which undergo big changes in concentration. In fact, opposite happens, it has limitation.

We used the sciatic nerve-tibialis anterior muscles in vivo and the phrenic nerve-diaphragms in vitro experiments. We used different muscles because it is difficult to measure twitch tension of diaphragm in vivo (the twitch is influenced by the movement of thorax) and because it is impossible for oxygen to diffuse in the tibialis anterior muscle in an organ bath as the muscle is not thin. The possibility that the difference in the block/fade relationship depends on differences between the limb and respiratory muscle can not be denied. Also, we realize that this study has been restricted to three steroidal NBAs of similar chemically structure. Thus, it is desirable that this work is extended to include non-steroidal NBAs of different chemical structure and metabolism, and with a short and long duration of action.

In conclusion, the prejunctional effects of pancuronium, vecuronium, and rocuronium are similar because the block/fade relationships are the same under pseudo-steady-state conditions. In contrast, under non-steady-state conditions, such as during recovery, the intrinsic TOF fade for each individual NBA was affected by a factor, possibly the rate of clearance in local drug concentrations, which exists in vivo, but not in vitro. We postulate that, within a series of structurally related compounds, longer recovery rates are associated with greater TOF fade. Non-depolarizing NBAs for shorter recovery rates are required to have less TOF fade to confirm the recovery.

\section{References}

1 Ali HH, Savarese JJ. Monitoring of neuromuscular function. Anesthesiology 1976; 45: 216-49.

2 Ali HH, Utting JE, Gray C. Stimulus frequency in the detection of neuromuscular block in humans. $\mathrm{Br} \mathrm{J}$ Anaesth 1970; 42: 967-78.

3 Power SJ, Pearce AC, Jones RM. Fade profiles during spontaneous offset of neuromuscular blockade: vecuronium and gallamine compared. Br J Anaesth 1988; 60: 486-90.

4 Gyermek L, Berman N. "Train-of-four" fade during clinical nondepolarizing neuromuscular block. Int J Clin Pharmacol Ther 1992; 30: 122-7.

5 Fletcher JE, Sebel PS, Mick SA, Van Duys J, Ryan K. Comparison of the train-of-four fade profiles produced by vecuronium and atracurium. Br J Anaesth 1992; 68: 207-8.

6 McCoy EP, Connolly FM, Mirakhur RK, Loan PB, Paxton $L D$. Nondepolarizing neuromuscular blocking drugs and train-of-four fade. Can J Anaesth 1995; 42: 213-6.

7 Galindo $A$. The role of prejunctional effects in myoneural transmission. Anesthesiology 1972; 36: 598-608.

8 Bowman WC, Webb SN. Tetanic fade during partial transmission failure produced by non-depolarizing neuromuscular blocking drugs in the cat. Clin Exp Pharmacol Physiol 1976; 3: 545-55.

$9 S u$ PC, $S u W-L$, Rosen $A D$. Pre- and postsynaptic effects of pancuronium at the neuromuscular junction of the mouse. Anesthesiology 1979; 50: 199-204.

10 Bowman WC. Prejunctional and postjunctional cholinoceptors at the neuromuscular junction. Anesth Analg 1980; 59: 935-43.

11 Baker T, Agnero A, Stanec A, Lowndes HE. Prejunctional effects of vecuronium in the cat. Anesthesiology 1986; 65: 480-4.

12 Pearce AC, Casson WR, Jones RM. Factors affecting train-of-four fade. Br J Anaesth 1985; 57: 602-6.

13 Williams NE, Webb SN, Calvey TN. Differential effects of myoneural blocking drugs on neuromuscular transmission. Br J Anaesth 1980; 52: 1111-5.

14 Stanec A, Baker T. Prejunctional and postjunctional effects of tubocurarine and pancuronium in man. $\mathrm{Br} \mathrm{J}$ 
Anaesth 1984; 56: 607-12.

15 Storella RJ, Slomowitz SA, Rosenberg $H$. Relationships between block-of-twitch and train-of-four fade in the mouse phrenic nerve-diaphragm preparation. Can J Anaesth 1991; 38: 401-7.

16 Foldes FF. The significance of physiological $\mathrm{Ca}^{2+}$ and $\mathrm{Mg}^{2+}$ for in vitro experiments on synaptic transmission. Life Sci 1981; 28: 1585-90.

17 Gibb AJ, Marshall IG. Pre- and post-junctional effects of tubocurarine and other nicotinic antagonists during repetitive stimulation in the rat. J Physiol (Lond) 1984; 351: 275-97.

18 Feldman $S$. Second thoughts on the train-of-four (Editorial). Anaesthesia 1993; 48:1-2.

19 Shiraishi H, Suzuki H, Suzuki T, Katsumata N, Ogawa $S$. Fading responses in the evoked EMG after rocuronium in cats. Can J Anaesth 1992; 39: 1099-104.

20 Gibb AJ, Marshall IG. Examination of the mechanisms involved in tetanic fade produced by vecuronium and related analogues in the rat diaphragm. Br J Pharmacol 1987; 90: 511-21.

21 Rupp SM, Castagnoli KP, Fisher DM, Miller RD. Pancuronium and vecuronium pharmacokinetics and pharmacodynamics in younger and elderly adults. Anesthesiology 1987; 67: 45-9.

22 McCoy EP, Mirakhur RK, Maddineni VR, Wierda $J M K H$, Proost JH. Pharmacokinetics of rocuronium after bolus and continuous infusion during halothane anaesthesia. Br J Anaesth 1996; 76: 29-33.

23 Power SJ, Jones RM. Relationship between single twitch depression and train-of-four fade: influence of relaxant dose during onset and spontaneous offset of neuromuscular blockade. Anesth Analg 1987; 66: 633-6.

24 Bartkowski RR, Epstein RH. Relationship between train-of-four ratio and first-twitch depression during neuromuscular blockade: a pharmacokinetic/dynamic explanation. J Pharmacokinet Biopharm 1990; 18: 335-46.

25 Graham GG, Morris R, Pybus DA, Torda TA, Woodey $R$. Relationship of train-of-four ratio to twitch depression during pancuronium-induced neuromuscular blockade. Anesthesiology 1986; 65: 579-83. 